\title{
DAC-EuCheMS Lecture Award presented to ABC author Lo Gorton
}

\author{
Nicola Oberbeckmann-Winter ${ }^{1}$ (iD \\ Published online: 16 April 2018 \\ (C) Springer-Verlag GmbH Germany, part of Springer Nature 2018
}

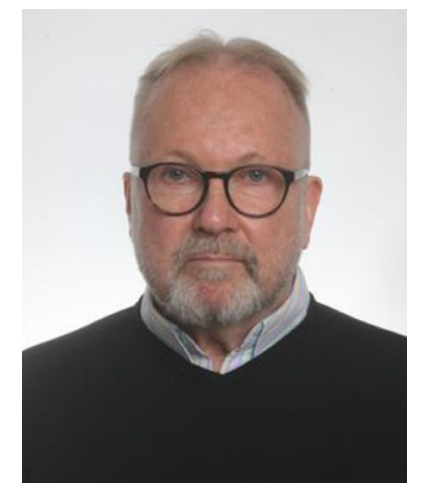

Lo Gorton is Professor Emeritus in Analytical Chemistry, Lund University, Sweden. Currently he is also the President of the Bioelectrochemical Society (BES). His main interest is bioelectrochemical studies of direct and mediated electron transfer reactions between redox enzymes, biological membranes, living cells, and electrodes, and applications thereof in biosensors, biofuel cells and biosupercapacitors.

The DAC-EuCheMS Lecture Award, sponsored by Springer-Verlag, recognizes a European individual who has demonstrated significant and sustained achievements in research or education in analytical chemistry throughout his or her career. Lo Gorton is the recipient of the 2017 DACEuCheMS Award. His lecture, entitled "Analytical tools based on electrochemical communication between enzymes/cells and electrodes", was presented at the XIX Euroanalysis held in Stockholm, Sweden, from August 28 to September 1, 2017.

Lo Gorton has talked to Nicola Oberbeckmann-Winter about his research, his motivation, and himself.

Nicola Oberbeckmann-Winter

nicola.oberbeckmann-winter@ springer.com

Analytical and Bioanalytical Chemistry, Springer Verlag, Tiergartenstrasse 17, 69121 Heidelberg, Germany

\section{What is the focus of your award-winning research and what was/is your motivation?}

The focus has always been how to facilitate and optimize the electron transfer rate between a biologically derived material (an enzyme, a membrane, a whole viable cell) and an electrode. My motivation was always pure curiosity.

\section{What is the trickiest problem you have had to overcome in that research? How did you solve it?}

The trickiest problem I had to overcome was back in the early 1980s and when I tried to understand the reaction mechanism between NADH and a redox mediator, Meldola Blue, which was adsorbed onto a graphite electrode. For each electrochemical experiment I performed, the rate constant that I could evaluate using standard electrochemical methodology between NADH and Meldola Blue was different. However, after spending a lot of time in the library, reading basic biochemistry on how NADH is oxidized within the living cell, I came to the conclusion that I should apply the Michaelis-Menten kinetic approach also on this reaction. By combining the electrochemical Koutecky-Levich equation with the Michaelis-Menten equation, I finally got very good and reproducible results and could propose that NADH initially forms a chargetransfer complex with Meldola Blue within which the $\mathrm{e}^{-}-\mathrm{H}^{+}$transfer occurs.

\section{From where did you start and how does your current work relate to/differ from your scientific roots?}

I started my graduate studies under the supervision of Professor Gillis Johansson, who in the 1970s introduced the use of enzymes in analytical chemistry in Sweden. 
My very first papers focused both on immobilized enzyme reactors (IMERs) and on (bio)electrochemistry. After continuing along both these directions, including combinations with flow injection analysis (FIA), liquid chromatography (HPLC), and mass spectrometry (MS) for many years, I finally decided to only specialize in bioelectrochemistry, leaving IMERs, HPLC, and MS behind.

\section{How would you explain your current research to a child?}

I would take a lemon and introduce two electrodes of different materials (e.g., a copper and a zinc electrode) into the lemon and attach these two electrodes to an electric circuit in which there is a low resistance lamp. When short-circuiting the system, the child will see the lamp glow. From that I will try to explain how the system works.

\section{Where do you consider your field is heading?}

Current bioelectrochemistry is a discipline combining cutting edge research in electrochemistry, biochemistry/ biology/microbiology, nanoscience, and materials chemistry. Within a few years, we will see major break throughs in how to use bioelectroanalytical chemistry to be able to follow the metabolism of mammalian/ human cells and how this can increase our understanding of what is going on within the cell. We will also see further break throughs in the energy sector through applications of microbial fuel cells for small and medium scale energy production.
Which recent discovery might prove most valuable to the field of bioanalytical research or beyond?

I would say if we can find good solutions on how to facilitate electron transfer reactions between viable mammalian cells and electrodes that would make it possible for us to understand cell metabolism in real-time.

\section{What motivated you to become a researcher and what do you find most rewarding in your professional life?}

In retrospect I am not so sure what made me stay in academia. Possibly one of the major reasons was that industry never wanted me. Most rewarding was always the close to daily contact with my students, many of them I still keep close contact with, which makes my life richer.

\section{What is your advice for young analytical scientists today?}

As long as you enjoy what you do - try to stay because I know that science is very rewarding. However, never mind the besserwissers and stay out of the academic intrigues.

\section{And last, but not least, what do you enjoy most when you have time to spare?}

Traveling (without any expectations to have to deliver any talk or participate in scientific discussions), listening to music, visiting the country house, seeing friends, and reading. 